\title{
Analysis of Heat Transfer Mechanisms in the Solidification of PCM with Different Passive Enhancement Techniques for Free Cooling Applications
}

\author{
Shafee.S.M.*, Gnanasekaran K, Ravikumar Solomon G, Balaji R \\ Department of Mechanical Engineering, Hindustan Institute of Technology and Science, Padur, India \\ Corresponding Author: shafee.sm@gmail.com, sridharabalaa@gmail.com
}

\begin{abstract}
The continuous increase in the level of greenhouse gas emissions and the depletion of fossil fuels are identified as the major driving forces behind efforts to effectively utilize different sources of renewable energy. Free cooling concept is gaining importance in building cooling applications. The medium which is used to store energy is Phase Change Material. Among the phase change materials available commercial PCM is of great use. The only drawback with the PCM is its thermal conductivity is very low. Various heat-transfer enhancement techniques between the phase change material (PCM) and the heat transfer fluid (HTF) were tried by researchers. Passive enhancement techniques are very simple and give good heat transfer enhancement that decreases the solidification time and increases the solidification rate. In the present work two types of passive enhancement techniques like increasing the roughness of the heat transfer surface and dimples over the heat transfer surface were tried and it has been observed that the dimpled surface will provide better results compared to rough surface over normal surface. Overall there is decrease in solidification time of $37 \mathrm{~min}$. and increase in solidification rate of $19.37 \%$ with dimpled surface over normal surface.
\end{abstract}

Keywords: Solidification, PCM, Rough Surface, Dimple Surface, Thermal Storage Unit

\section{Introduction}

In the current scenario, Latent heat storage system employing phase change materials is one of the energy saving technology. The process of storing the cool energy after the sunset and releasing the same for cooling the buildings during daytime is referred as free cooling. Phase change materials having the above property, find potential application in the field of heating, ventilation and air conditioning (HVAC). Paraffin, one of the commonly used organic phase change material exhibits high thermal storage capacity, chemical stability and low sub cooling. The major limitation despite the above merits is its poor thermal conductivity. One of the techniques for heat transfer enhancement is passive techniques like creating rough surface and adding dimples on the surface. Chen et.al [1] in his experimental work on coaxial pipe heat exchanger used dimples as the heat transfer modification of inner tube. After conducting experiment, a correlation was proposed which accurately predicts the heat transfer coefficient and friction of dimpled tube heat exchanger. Burgess et.al [2] conducted experiment with dimpled test surfaces placed on one wall of different channels.
Experiments are carried out to illustrate the effect of Reynolds number, and stream wise development for dimple depth to dimple diameter $(\delta / D)$ for $0.1,0.2$ and 0.3 ratios. It has been found variations with Reynolds number are mostly apparent on flat surfaces just downstream of individual dimples. Small et.al [3] in his study on heat sinks for cooling of mock processors, evaluated the thermal performance of heat sink experimentally and numerically with and without dimples. Result of the work shows dimples improve the heat transfer capability of heat sinks with slight drop in pressure. Wei et.al [4] numerically studied the heat transfer inside a rectangular microchannel with dimpled bottom surface. It has been found that the dimples provide an effective passive heat transfer augmentation for macroscale channels, and can also be used to enhance heat transfer inside microchannels. Solomon et.al [5] concluded that a fin height of approximately $60 \%$ of the annual gap is enhancing the solidification heat transfer by a maximum of $22.1 \%$ and suppressing the free convection prior to solidification. Arkar et.al [6] conducted experimental work on cylindrical Latent Heat Thermal Energy Storage System (LHTES) with paraffin filled in spheres. The investigation was carried with both experimental and numerical analysis and it has been concluded that phase change material's thermal properties plays very important role in the work. Solomon et.al [7] observed that higher cooling rate increases the sub cooling effect. The PCM located the farthest away from the heat transfer surfaces had a much higher temperature gradient and a longer time span. So a large portion of the PCM was cooled below the phase change temperature before the solidification process was initiated. Subsequently the temperature of the PCM increased. When the driving potential between the PCM and the fluid was increased, the subsequent increase in the inlet velocity had little or no effect during the liquid sensible cooling and therefore, the subsequent solidification process. Giram et.al [8] in his experimental work studied the heat transfer characteristics and pressure drop on six dimpled plates subjected to forced convection and of varying densities. It was found that Nusselt number increases with increase in dimple density and percentage increase is high for staggered dimple arrangement.

Chinaruk et.al [9] conducted experimental work on dimpled tube fitted with twisted tape swirl generator and founded the friction and compound heat transfer behaviour of the above with air as the working fluid. The experimental results show 
both heat transfer coefficient and friction factor in the dimpled tube fitted with the twisted tape, are higher than those in the dimple tube acting alone and plain tube. Also it has been reported that the heat transfer coefficient and friction factor in the combined devices increase as the pitch ratio and twist ratio decrease. Prasad et.al [10] in his experimental work found that Convective heat transfer coefficient between absorber plate and air in a flat-plate solar air heater can be enhanced by providing the absorber plate with artificial roughness. Li et.al [11] in his experimental work studied the mechanism of turbulent convective heat transfer enhancement by measuring the heat transfer in two dimensional roughness tubes with different roughness heights at various Reynolds numbers. It has been reported that best heat transfer enhancement for a given pumping power is observed when the height of roughness is three 6655times of viscous sublayer thickness.

\section{Arrangement of Thermocouples}

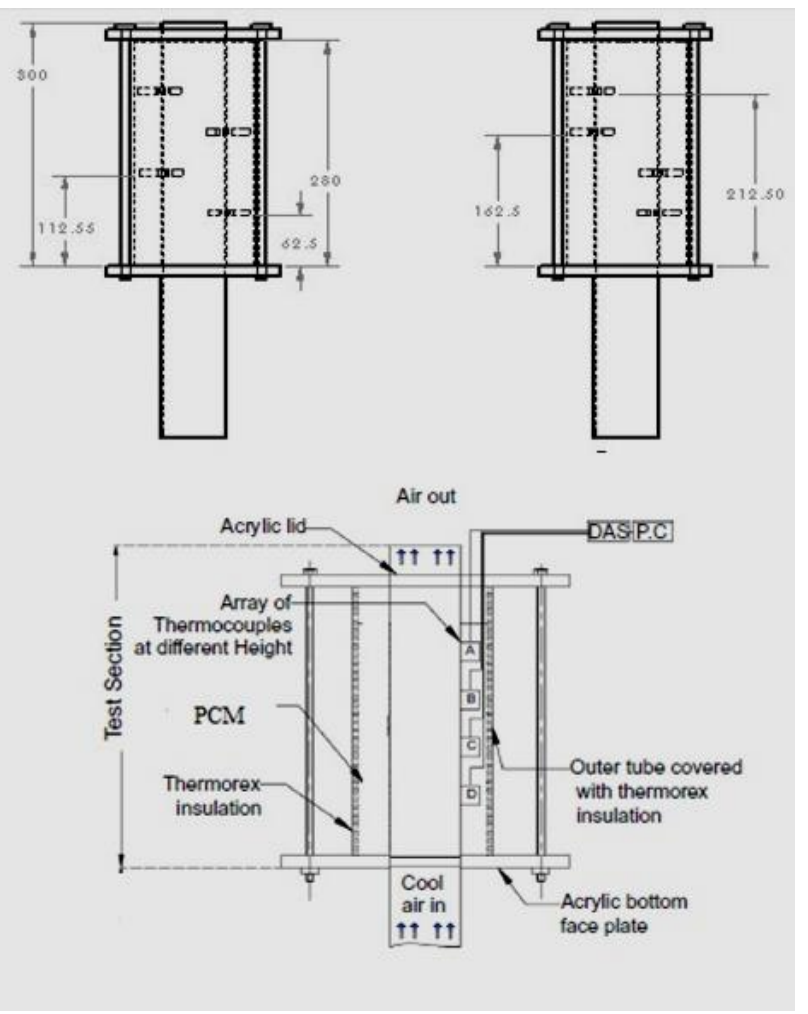

Fig.1 Schematic Diagram on the Arrangement of Thermocouples

\section{Material and Methods}

\section{Experimental Setup}

The experimental setup consisted of a test section, and the HTF flow control section, that regulated the flow through the inner tube of the test section. The test section was a double pipe annular heat exchanger, comprising an inner copper tube with an OD of $80 \mathrm{~mm}$, thickness $1.5 \mathrm{~mm}$ and height $300 \mathrm{~mm}$ and an outer acrylic tube of OD of $150 \mathrm{~mm}$, thickness $5 \mathrm{~mm}$ and height of $280 \mathrm{~mm}$. The PCM (RT21), which was in the liquid state at room temperature, was filled to height of $245 \mathrm{~mm}$ in annular space. The phase change material used to store the heat energy was paraffin, commercially known as RT21, obtained from Rubitherm, Germany. It is chemically inert and stable, nontoxic, and inorganic compound.

The liquid PCM did not require any clearance volume in annular space, as the volume contracts by about $14 \%$ during solidification. The bottom side of the inner tube was externally threaded, and assembled with an acrylic bottom face plate of $10 \mathrm{~mm}$ thickness, which was internally threaded.

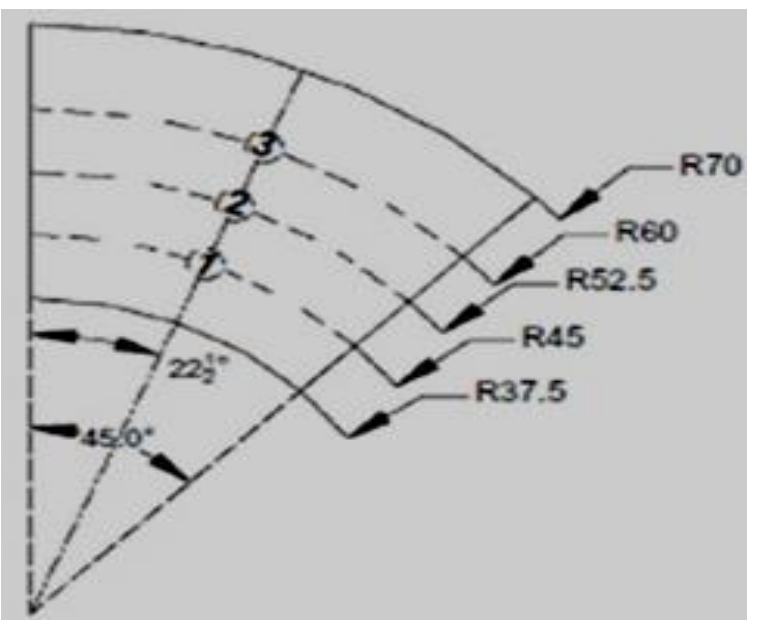

Fig.2 Angle on Arrangement of Thermocouple

The outer acrylic tube was also fixed on the bottom face plate, in a ring groove to ensure proper sealing. The PCM filled outer acrylic container was covered with an acrylic lid of $80 \mathrm{~mm}$ ID, $150 \mathrm{~mm}$ OD and $10 \mathrm{~mm}$ thickness. Three layer of $3 \mathrm{~mm}$ thickness thermorex insulation were tightly wrapped on the outer acrylic tube to provide perfect insulation, the concentric cylinder was fastened using 4 bolts and nuts as shown in Fig. 2.1

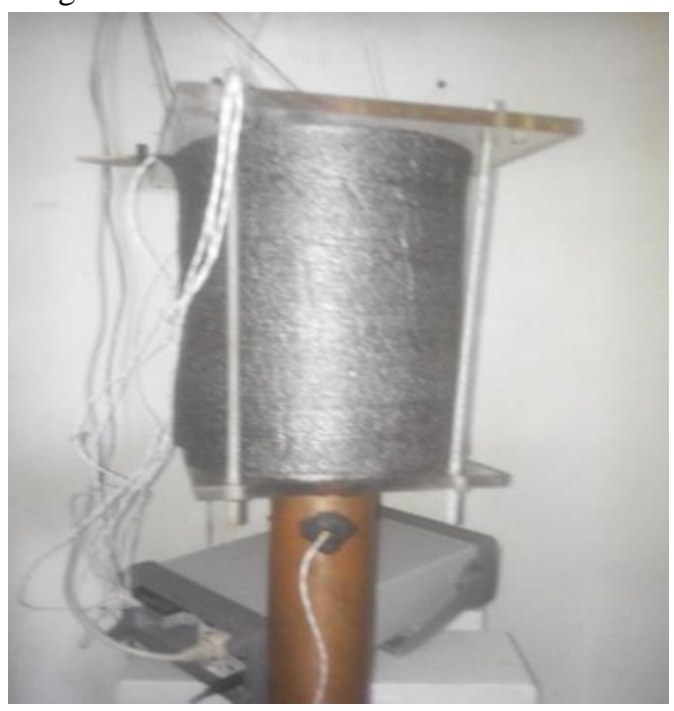

Fig.2.1 Test section 
The HTF flow control section consisted of an entry length tube, a conical diffuser and a flow straightening section. The entry length tube made of copper, identical in dimensions to the inner tube, was attached at the bottom of the face plate. The conical GI diffuser having a major diameter of $300 \mathrm{~mm}$ and a minor diameter of $75 \mathrm{~mm}$ was fixed at the bottom of the entry length tube and this is fixed to the coupler. At the bottom of the conical GI diffuser, the flow straightener having 400 holes, each of $3 \mathrm{~mm}$ diameter, and $150 \mathrm{~mm}$ height was fixed. The above arrangement was supported rigidly on a $50 \mathrm{~mm}$ thick wooden platform as shown in Fig. 2.2.

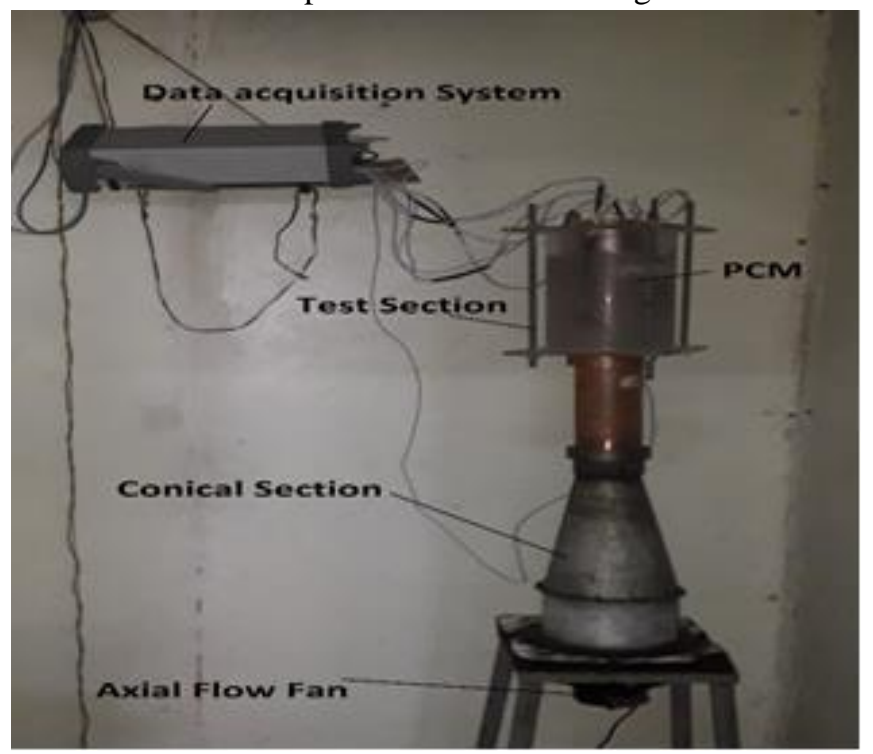

Fig.2.2 Experimental Setup

\section{Experimental Procedure}

During the start of each experimental trial, the ambient air was circulated through the test section until all the thermocouples located in the PCM regions attained the same temperature, whereby the thermal equilibrium of the PCM was ensured. The climatic simulator was switched on, to reduce the space temperature to the required level. Then the blower was switched on, and the flow rate was obtained by applying the pre-determined set voltage, which was maintained at a constant level throughout the experiment. The temperature measurements at all the thermocouple locations were continuously monitored using the Data Acquisition System (DAS). The experiments were conducted at two HTF inlet temperatures $\left(12^{\circ} \mathrm{C}, 11^{\circ} \mathrm{C}\right)$ and two HTF inlet velocities $(6 \mathrm{~m} / \mathrm{s}$, $5 \mathrm{~m} / \mathrm{s})$. The surface heat flux was varied with the combination of the HTF inlet temperature and its velocity. A higher inlet temperature and lower inlet velocity resulted in Low Heat Flux (LHF), while lower inlet temperature and higher inlet velocity resulted in High Heat Flux (HHF) among the tested parameters. In most of the experimental conditions, there was no deviation in the readings when the experiments were repeated. In case of variation in some trials, the experiments were continued till the repeatability of the readings was ensured.

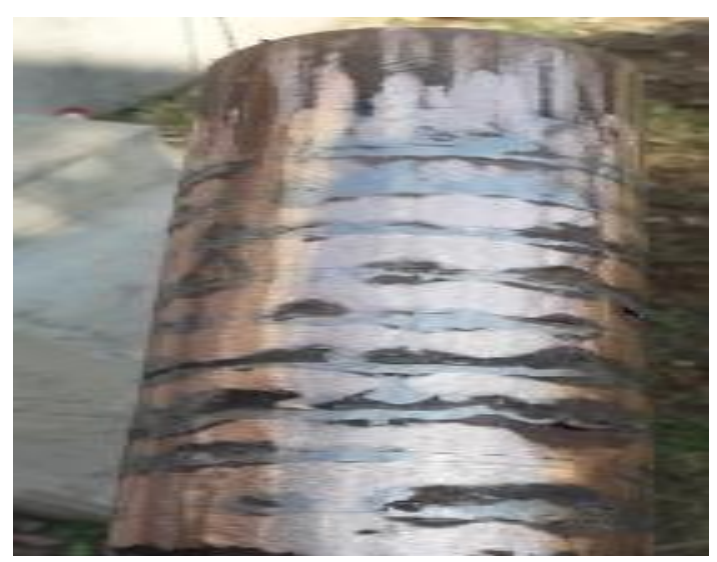

Fig. 2.4 Rough Copper Tube with Roughness Value of 8 to $10 \mu \mathrm{m}$

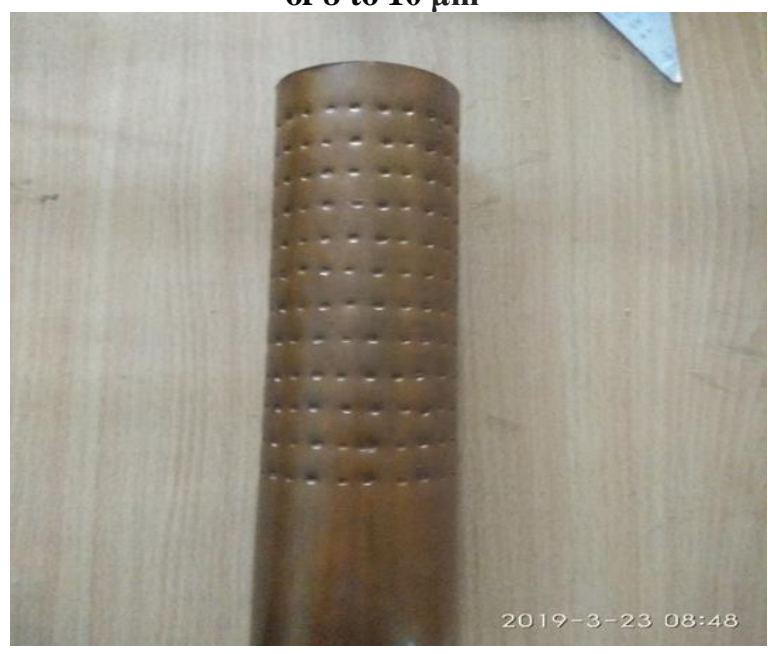

Fig.2.5 Circular Dimpled Surface

\section{RESULTS AND DISCUSSION}

3.1 COMPARISON OF AVERAGE SOLIDIFICATION

TIME 


\begin{tabular}{|c|c|c|c|c|c|c|c|c|c|c|c|c|c|c|c|}
\hline \multirow{2}{*}{$\begin{array}{c}\text { Type of Copper } \\
\text { Surface }\end{array}$} & \multirow[b]{2}{*}{ S.no } & \multirow{2}{*}{ Constraints } & \multicolumn{13}{|c|}{ Time taken for Solidification of PCM at Various Locations $\left(21^{\circ} \mathrm{C}\right.$ to $\left.18^{\circ} \mathrm{C}\right)$ in Minutes } \\
\hline & & & A1 & $\mathbf{A 2}$ & $\mathbf{A 3}$ & B1 & B2 & B3 & C1 & C2 & C3 & D1 & D2 & D3 & Average \\
\hline \multirow{4}{*}{$\begin{array}{c}\text { Normal Copper } \\
\text { Tube with Surface } \\
\text { Roughness of 2- } \\
3 \mu \mathrm{m}\end{array}$} & 1 & $11^{\circ} \mathrm{C} @ 5 \mathrm{~m} / \mathrm{s}$ & 125 & 7 & 168 & 165 & 193 & 189 & 147 & 187 & 203 & 115 & 178 & 201 & \\
\hline & 2 & & 20 & & 155 & 3 & 148 & 58 & 120 & 151 & 164 & 7 & 34 & 151 & \\
\hline & 3 & & 14 & & 191 & 200 & & & & & & 135 & 2 & 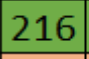 & \\
\hline & 4 & $\mathrm{l} / \mathrm{s}$ & 7 & 7 & 168 & 188 & 219 & 6 & 5 & 210 & 229 & 9 & 166 & 9 & 2 \\
\hline \multirow{4}{*}{$\begin{array}{c}\text { Copper Tube with } \\
\text { Surface } \\
\text { Roughness } \\
\text { beyond } 8 \mu \mathrm{m}\end{array}$} & 1 & $11^{\circ} \mathrm{C} @ 5 \mathrm{~m} / \mathrm{s}$ & 107 & 130 & 145 & 93 & 151 & 169 & 114 & 159 & 172 & 73 & 147 & 165 & 7 \\
\hline & 2 & $11^{\circ} \mathrm{C} @ 6 \mathrm{~m} / \mathrm{s}$ & 101 & 130 & 150 & 92 & 147 & 159 & 106 & 153 & 159 & 71 & 160 & 171 & 25 \\
\hline & 3 & $12^{\circ} \mathrm{C} @ 5 \mathrm{~m} / \mathrm{s}$ & 127 & & 176 & 116 & 171 & 187 & 136 & 185 & 198 & 101 & 188 & 203 & \\
\hline & 4 & $12^{\circ} \mathrm{C} @ 6 \mathrm{~m} / \mathrm{s}$ & 109 & 150 & 165 & 70 & 167 & 179 & 116 & 179 & 191 & 54 & 182 & 197 & \\
\hline \multirow{4}{*}{$\begin{array}{c}\text { Copper Tube with } \\
\text { Densely Dimpled } \\
\text { Surface }\end{array}$} & 1 & $11^{\circ} \mathrm{C} @ 5 \mathrm{~m} / \mathrm{s}$ & 102 & 122 & 140 & 71 & 149 & 147 & 130 & 159 & 179 & 119 & 155 & 165 & .50 \\
\hline & 2 & $11^{\circ} \mathrm{C} @ 6 \mathrm{~m} / \mathrm{s}$ & 97 & 115 & 131 & 68 & 144 & 144 & 129 & 172 & 165 & 106 & 155 & 165 & 58 \\
\hline & 3 & $12^{\circ} \mathrm{C} @ 5 \mathrm{~m} / \mathrm{s}$ & 122 & 141 & 154 & 90 & 173 & 173 & 156 & 195 & 210 & 134 & 185 & 198 & 160.92 \\
\hline & 4 & $12^{\circ} \mathrm{C} @ 6 \mathrm{~m} / \mathrm{s}$ & 108 & 130 & 145 & 85 & 164 & 164 & 145 & 191 & 208 & 114 & 177 & 193 & 152.00 \\
\hline
\end{tabular}

Table 3.1 Comparison of Solidification Time at all the Positions with Normal, Rough and Dimpled Surface

The solidification time at various positions and the average value of solidification time of PCM in three types of copper surfaces which are Normal, Rough, dimpled are tabulated in the table.

- At inlet temperature of $11^{\circ} \mathrm{C}$ and inlet air velocity of 5 $\mathrm{m} / \mathrm{s}$, the average solidification time of PCM with rough surface is compared with normal surface, the average solidification time has been decreased by 33.58 minutes and rate of solidification is increased by $19.86 \%$. On comparing dimpled surface with normal surface, the average solidification time has been decreased by 32 minutes and rate of solidification is increased by $19.23 \%$.

- At inlet temperature of $11^{\circ} \mathrm{C}$ and inlet air velocity of 6 $\mathrm{m} / \mathrm{s}$, the average solidification time of PCM with rough surface is compared with normal surface, the average solidification time has been decreased by 0.92 minutes and rate of solidification is increased by $0.7 \%$. On comparing dimpled surface with normal surface, the average solidification time has been decreased by 1.58 minutes and rate of solidification is increased by $1.18 \%$.

- At inlet temperature of $12^{\circ} \mathrm{C}$ and inlet air velocity of $5 \mathrm{~m} / \mathrm{s}$, the average solidification time of PCM with rough surface is compared with normal surface, the average solidification time has been decreased by 33 minutes and rate of solidification is increased by $16.92 \%$. On comparing dimpled surface with normal surface, the average solidification time has been decreased by 34 minutes and rate of solidification is increased by $17.48 \%$.

- At inlet temperature of $12^{\circ} \mathrm{C}$ and inlet air velocity of $6 \mathrm{~m} / \mathrm{s}$, the average solidification time of PCM with rough surface is compared with normal surface, the average solidification time has been decreased by 30.34 minutes and rate of solidification is increased by $17.15 \%$. On comparing dimpled surface with normal surface, the average solidification time has been decreased by 24.92 minutes and rate of solidification is increased by $14.1 \%$. Therefore, with this comparison dimpled surface on copper tube leading to provide better results in all the constraints

\subsection{EFFECT OF VARIATION IN TEMPERATURE AT} A3 (Farthest position from Entry region)

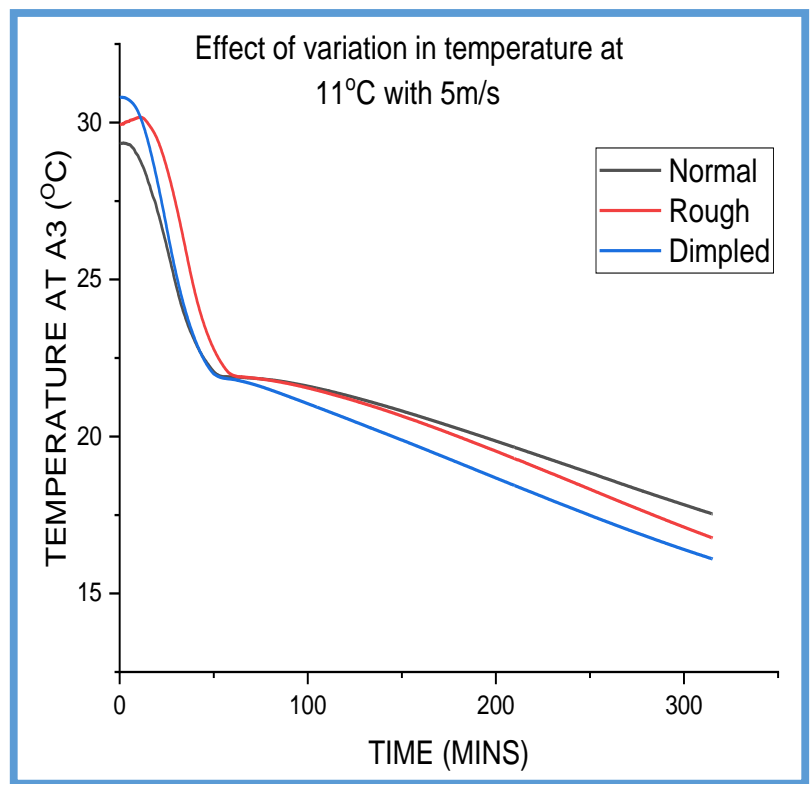




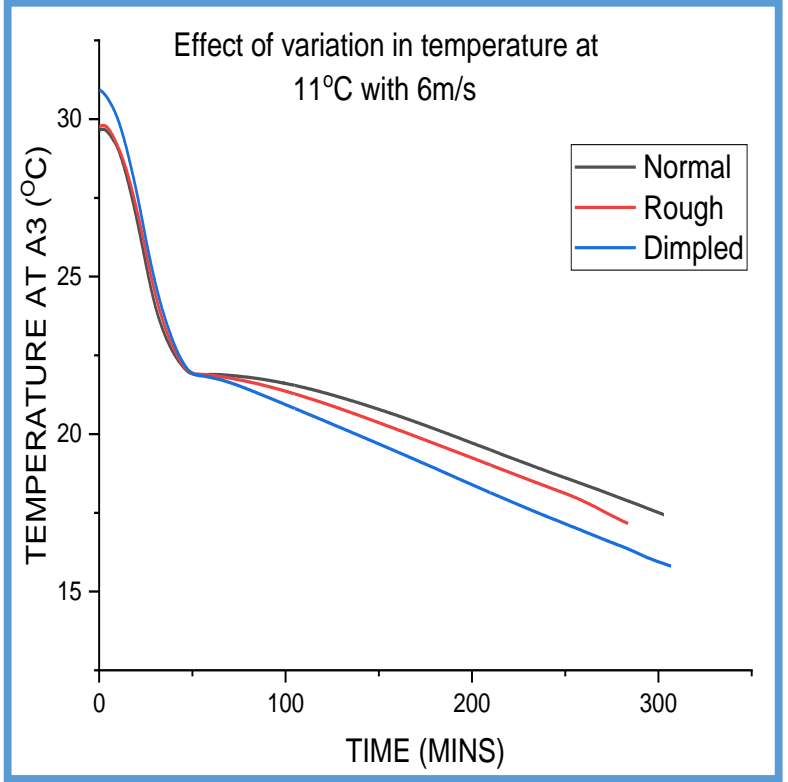

Fig. 3.1 Effect of Variation in Temperature at $\mathrm{A3}$ with $11^{\circ} \mathrm{C}$ with $5 \mathrm{~m} / \mathrm{s}$ and $6 \mathrm{~m} / \mathrm{s}$

- At inlet temperature of $11^{\circ} \mathrm{C}$ and the inlet velocity of air at $5 \mathrm{~m} / \mathbf{s}$, the variation of temperature with respect to time is plotted in Fig 3.1. The rate of decrease in temperature at $\mathrm{A} 3$ is observed to be faster in dimpled surface compared to the rough and normal surface. On comparing rough surface with normal surface, the solidification time has been decreased by 23 minutes and rate of solidification is increased by $13.7 \%$. On comparing dimpled surface with normal surface, the solidification time has been decreased by 28 minutes and rate of solidification is increased by $\mathbf{1 6 . 7 \%}$. Therefore, dimpled surface is much better comparing with others.

- At inlet temperature of $11^{\circ} \mathrm{C}$ and the inlet velocity of air at $6 \mathbf{m} / \mathbf{s}$, the variation of temperature with respect to time is plotted and shown again in Fig.3.1. The rate of decrease in temperature at $\mathrm{A} 3$ is observed to be faster in dimpled surface compared to the rough and normal surface. On comparing rough surface with normal surface, the solidification time has been decreased by 5 minutes and rate of solidification is increased by $\mathbf{3 . 2 \%}$.

- On comparing dimpled surface with normal surface, the solidification time has been decreased by 24 minutes and rate of solidification is increased by $\mathbf{1 5 . 4 \%}$.
Therefore, dimpled surface is much better comparing with others.

\subsection{EFFECT OF VARIATION IN TEMPERATURE AT}

\section{A3 (Farthest position from Entry region)}

(with temperature $12^{\circ} \mathrm{C}$ and velocity $5 \mathrm{~m} / \mathrm{s}$ and $6 \mathrm{~m} / \mathrm{s}$ )

- At inlet temperature of $12^{\circ} \mathrm{C}$ and the inlet velocity of air at $5 \mathrm{~m} / \mathrm{s}$, the variation of temperature with respect to time is plotted in fig 3.2. The rate of decrease in temperature at $\mathrm{A} 3$ is observed to be faster in dimpled surface compared to the rough and normal surface. On comparing rough surface with normal surface, the solidification time has been decreased by 15 minutes and rate of solidification is increased by $7.85 \%$. On comparing dimpled surface with normal surface, the solidification time has been decreased by 37 minutes and rate of solidification is increased by $19.37 \%$. Therefore, dimpled surface is much better comparing with others.

- At inlet temperature of $12^{\circ} \mathrm{C}$ and the inlet velocity of air at $6 \mathrm{~m} / \mathrm{s}$, the variation of temperature with respect to time is plotted in fig 3.2. The rate of decrease in temperature at A3 is observed to be faster in dimpled surface compared to the rough and normal surface. On comparing rough surface with normal surface, the solidification time has been decreased by 3 minutes and rate of solidification is increased by $1.78 \%$. On comparing dimpled surface with normal surface, the solidification time has been decreased by 23 minutes and rate of solidification is increased by $13.7 \%$.

Compared on the overall result at $\mathrm{A} 3$, the dimpled surface is far superior than the normal surface with highest decrease in solidification time of 37 minutes and increase of rate of solidification by $19.37 \%$. This is obtained at $12^{\circ} \mathrm{C}$ with inlet velocity of $5 \mathrm{~m} / \mathrm{s}$. 

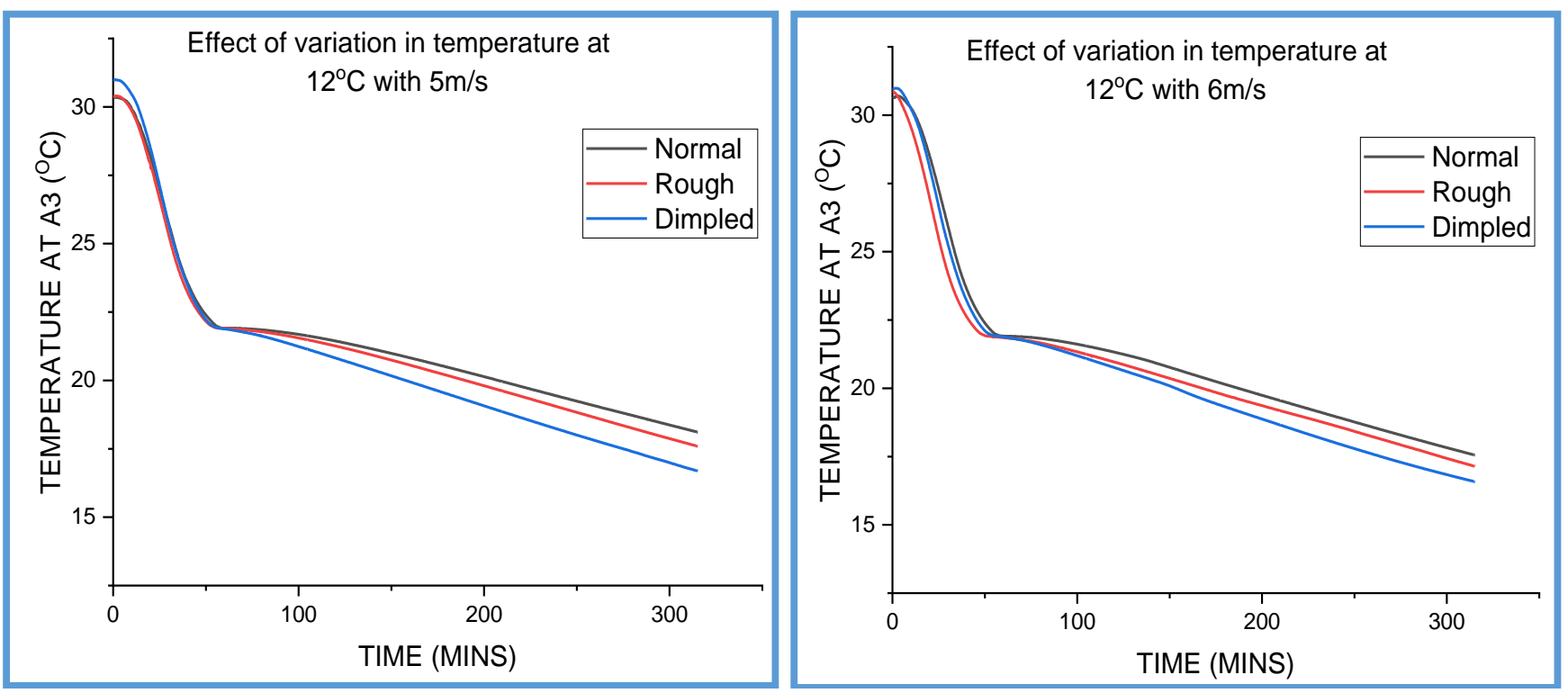

Fig. 3.2 Effect of Variation in Temperature at A3 with $12^{\circ} \mathrm{C}$ with $5 \mathrm{~m} / \mathrm{s}$ and $6 \mathrm{~m} / \mathrm{s}$

\section{VARIATION OF TEMPERATURE AT VARIOUS} POSITIONS WITH VARIOUS CONSTRAINTS

The following graph are plotted to show the variations of change in temperature of PCM at various axial and radial positions as mentioned in the experimental procedure. The various environmental constraints are $11^{\circ} \mathrm{C}$ with $5 \mathrm{~m} / \mathrm{s} ; 11^{\circ} \mathrm{C}$ with $6 \mathrm{~m} / \mathrm{s} ; 12^{\circ} \mathrm{C}$ with $5 \mathrm{~m} / \mathrm{s} ; 12^{\circ} \mathrm{C}$ with $6 \mathrm{~m} / \mathrm{s}$.

\subsection{NORMAL SURFACE OF COPPER TUBE}

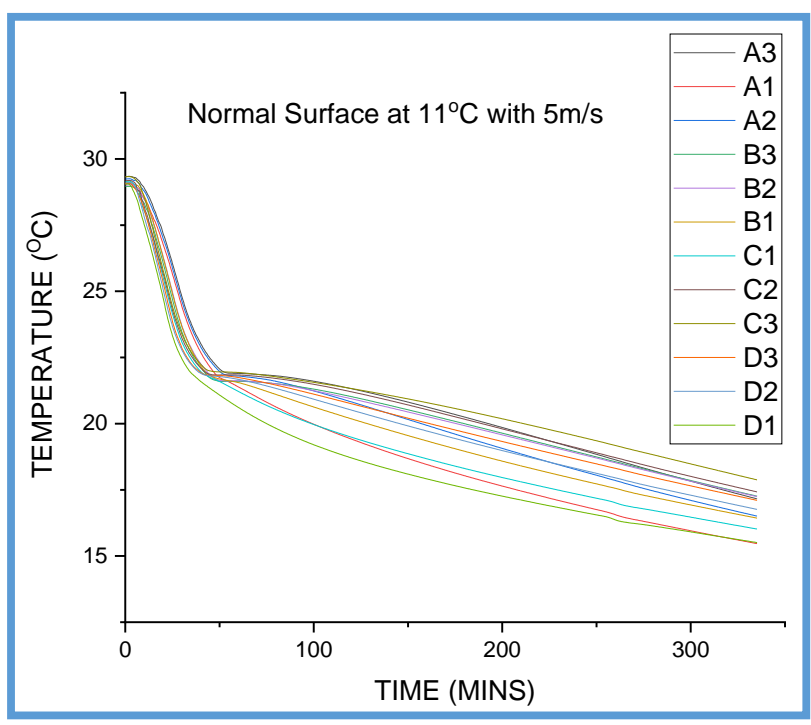

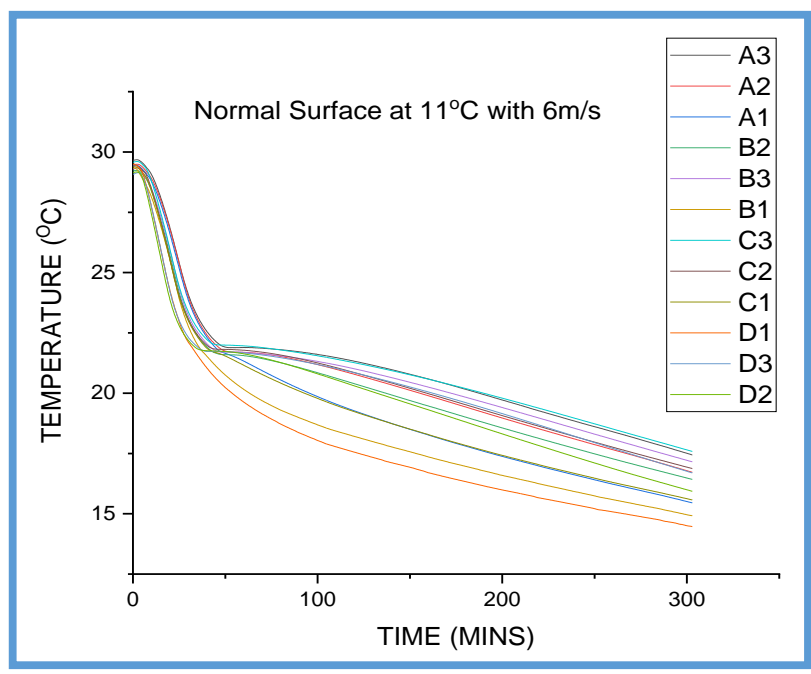

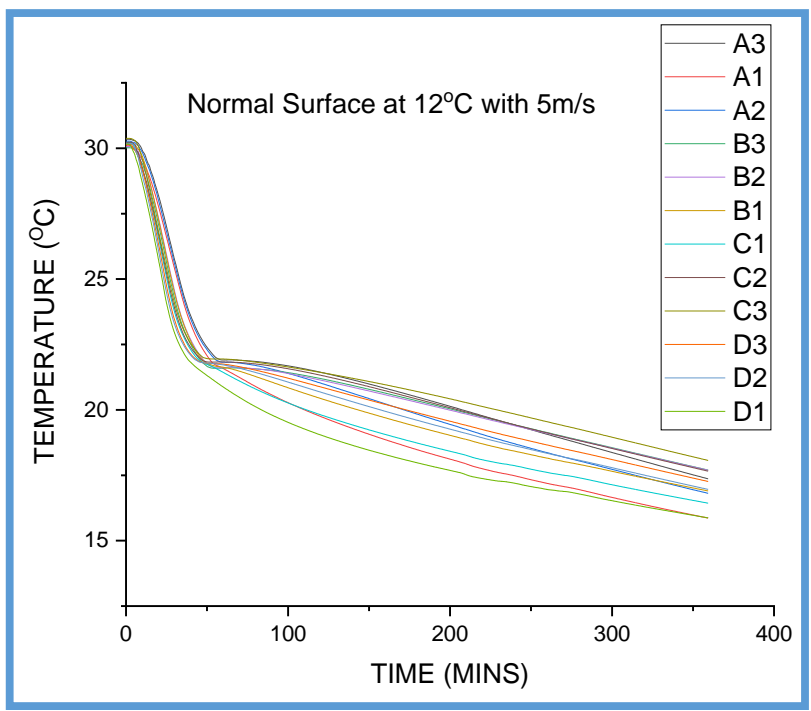




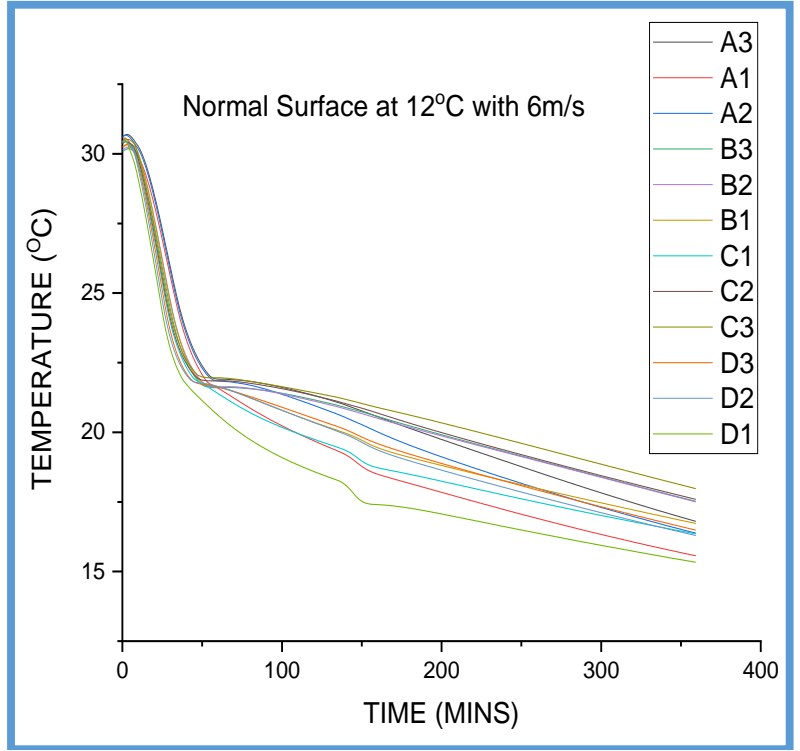

Fig.4.1 Normal Surface at $12^{\circ} \mathrm{C}$ with $6 \mathrm{~m} / \mathrm{s}$

\subsection{ROUGH SURFACE OF COPPER TUBE}
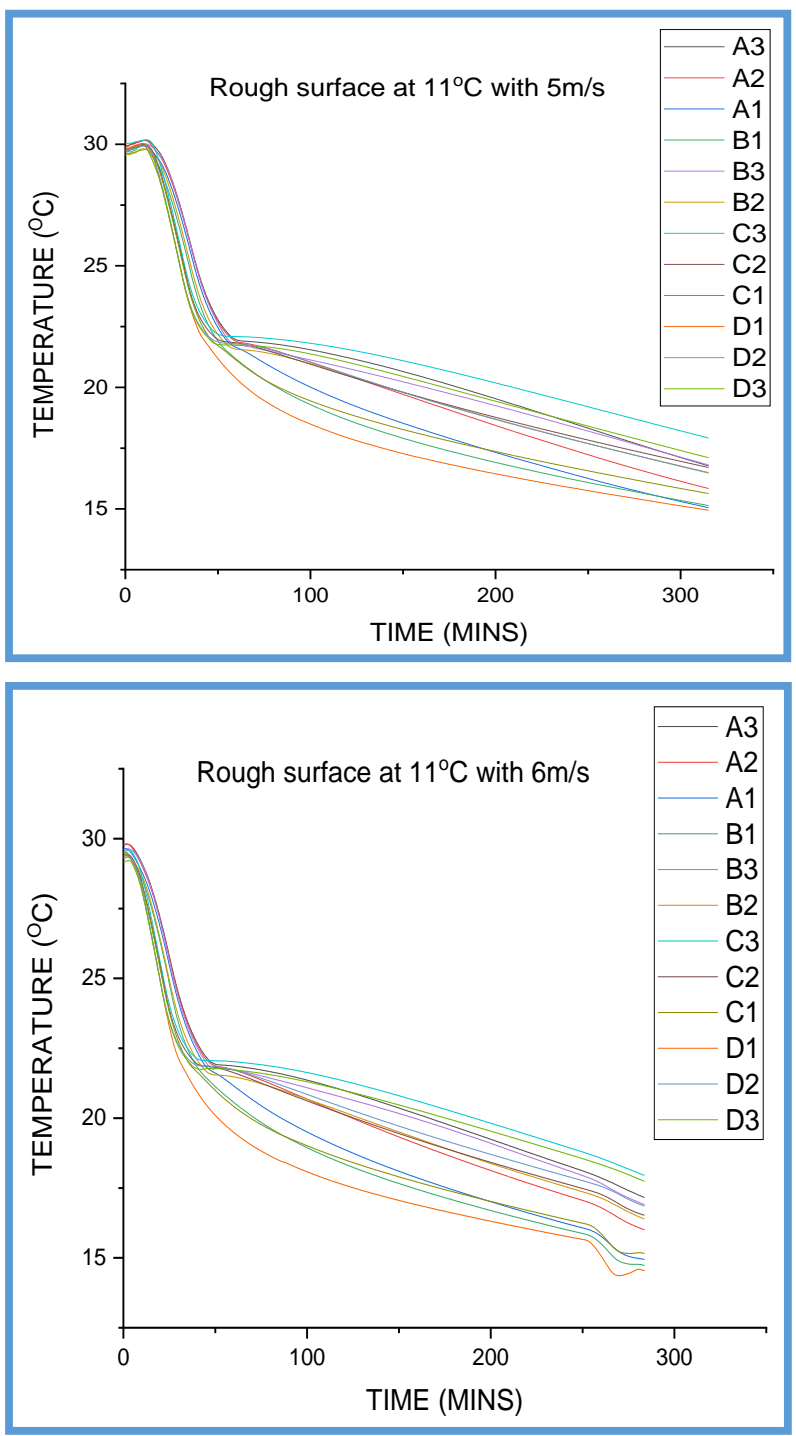
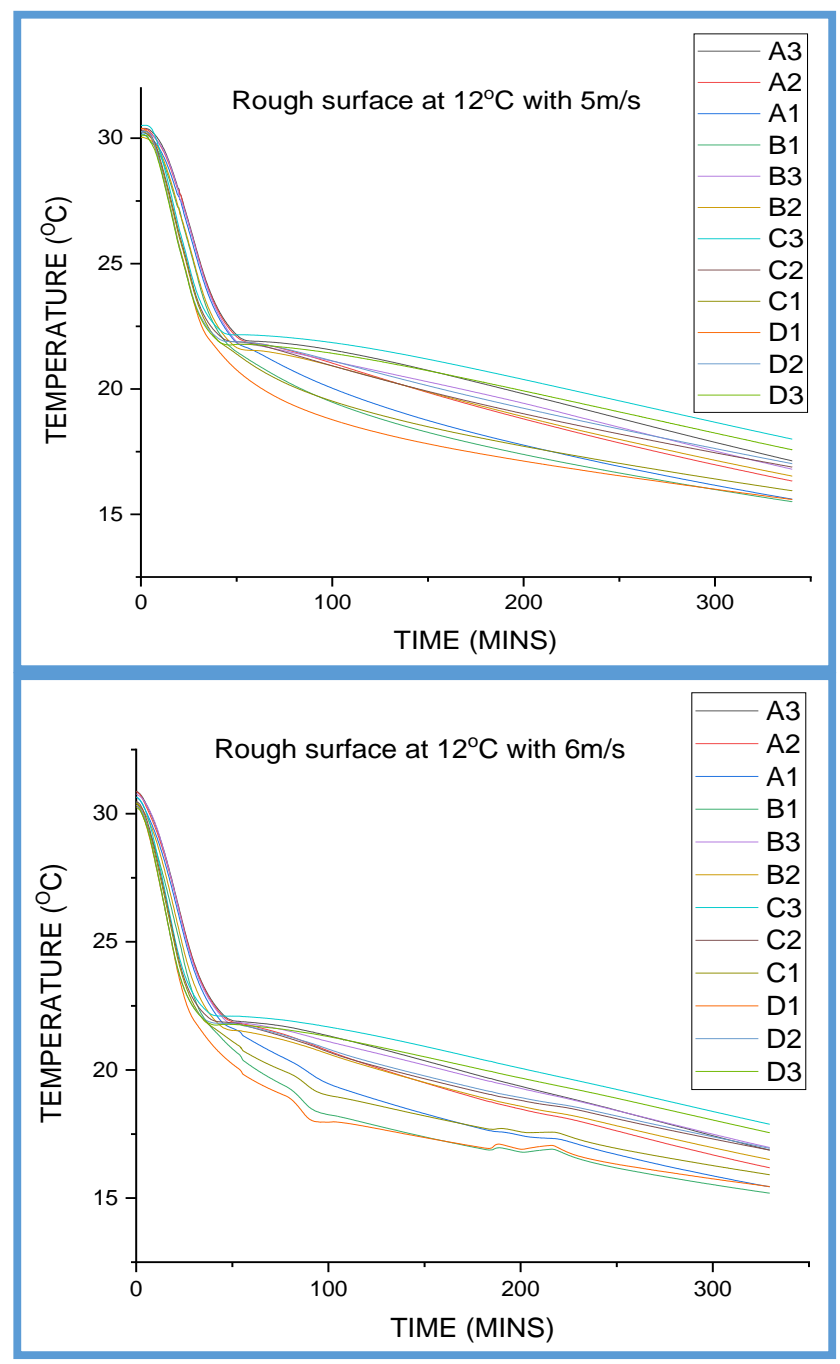

Fig. 4.2 Rough Surface at $11^{\circ} \mathrm{C}$ and $12^{\circ} \mathrm{C}$ with $5 \mathrm{~m} / \mathrm{s}$ and $6 \mathrm{~m} / \mathrm{s}$

\subsection{DIMPLED SURFACE OF COPPER TUBE}

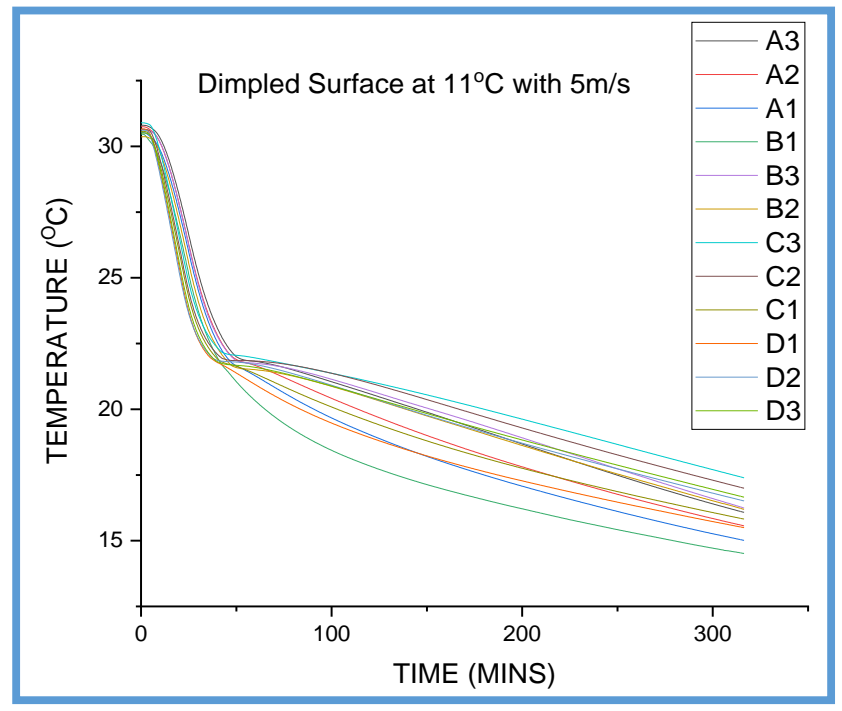



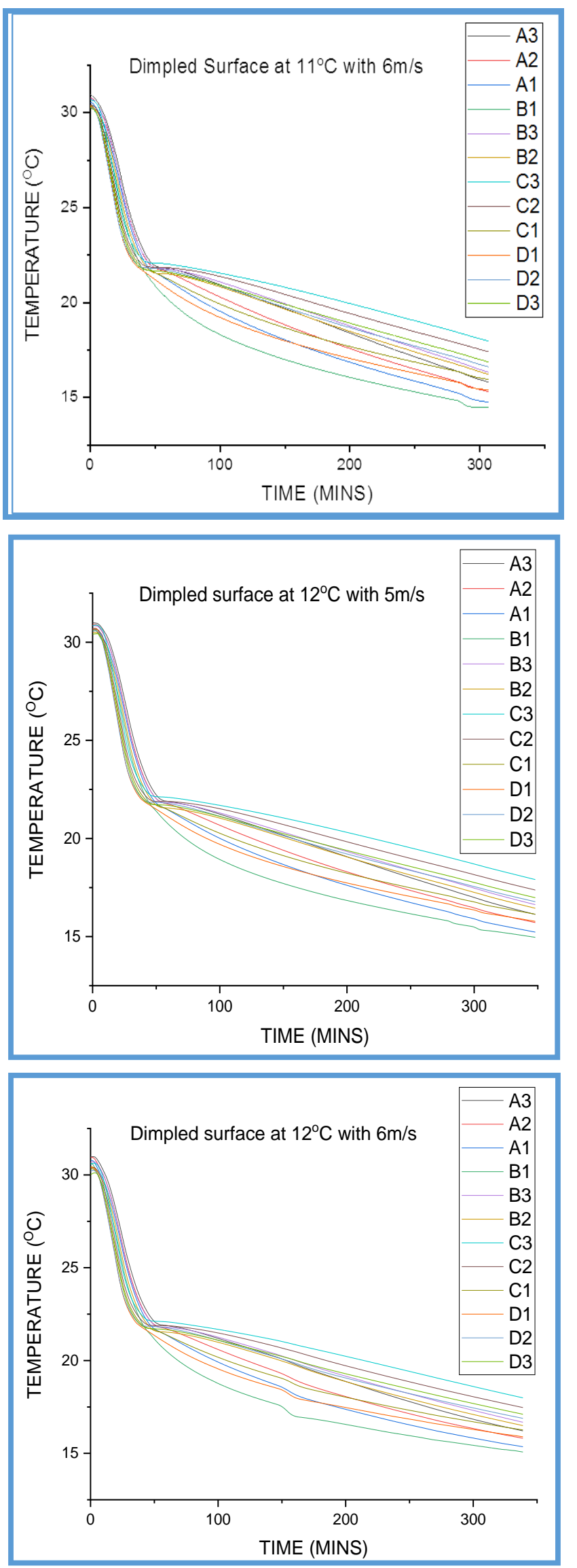

Fig. 4.3 Dimpled Surfaces at $11^{\circ} \mathrm{C}$ and $12^{\circ} \mathrm{C}$ with $5 \mathrm{~m} / \mathrm{s}$ and $6 \mathrm{~m} / \mathrm{s}$
Therefore, among the variations plotted in Fig 4.1, Fig. 4.2 and Fig. 4.3 above for temperature change with respect to time, the sub cooling effect observed in all the cases is almost negligible. And also, the dimpled surface gives better heat transfer enhancement compared to other two cases i.e., normal surface and surface with increased roughness.

Therefore, among the variations plotted in Fig 4.1, Fig. 4.2 and Fig. 4.3 above for temperature change with respect to time, the sub cooling effect observed in all the cases is almost negligible. And also, the dimpled surface gives better heat transfer enhancement compared to other two cases i.e., normal surface and surface with increased roughness.

\section{CONCLUSION}

The following conclusions are made from the experimental investigation carried out, to study the heat transfer in the PCM during the outward cylindrical solidification in a double pipe heat exchanger, with the PCM filled in the annulus and air as the HTF passing through the inner tube. The results are applicable for the inlet air velocity range of $5 \mathrm{~m} / \mathrm{s}, 6 \mathrm{~m} / \mathrm{s}$, and for the range of the driving temperature potential difference of $11^{\circ} \mathrm{C}-12{ }^{\circ} \mathrm{C}$. Though the results of the present study are useful for several applications, they have a direct relevance for the free cooling application of buildings, during the charging process, with air as the HTF.

- The experimental observation of solidification of temperatures at various cooling rates are achieved under different operating conditions with normal, dimpled and rough copper surfaces.

- Among normal, rough and dimpled surface the better results are obtained for dimpled surface due to high heat transfer rate by increasing the contact area and this helps in reducing the solidification time.

- Similarly comparing rough and normal surface the better results are obtained for rough surface due to increase in contact area of the surface. 


\section{References}

[1] Chen, J., Müller-Steinhagen, H., \& Duffy, G. G. (2001). Heat transfer enhancement in dimpled tubes. Applied thermal engineering, 21(5), 535-547.

[2] Burgess, N. K., \& Ligrani, P. M. (2004, January). Effects of dimple depth on Nusselt numbers and friction factors for internal cooling in a channel. In ASME Turbo Expo 2004: Power for Land, Sea, and Air (pp. 989-998). American Society of Mechanical Engineers.

[3] Small, E., Sadeghipour, S. M., \& Asheghi, M. (2006). Heat sinks with enhanced heat transfer capability for electronic cooling applications. Journal of electronic packaging, 128(3), 285-290.

[4] Wei, X. J., Joshi, Y. K., \& Ligrani, P. M. (2007). Numerical simulation of laminar flow and heat transfer inside a microchannel with one dimpled surface. Journal of Electronic Packaging, 129(1), 63-70.

[5] Solomon, G. R., \& Velraj, R. (2013). Analysis of the heat transfer mechanisms during energy storage in a Phase Change Material filled vertical finned cylindrical unit for free cooling application. Energy conversion and management, 75, 466-473.

[6] Arkar, C., \& Medved, S. (2005). Influence of accuracy of thermal property data of a phase change material on the result of a numerical model of a packed bed latent heat storage with spheres. Thermochimica Acta, 438(1-2), 192-201.

[7] Solomon, G. R., Karthikeyan, S., \& Velraj, R. (2013). Sub cooling of PCM due to various effects during solidification in a vertical concentric tube thermal storage unit. Applied Thermal Engineering, 52(2), 505-511.

[8] Giram, D. R., \& Patil, A. M. (2013). Experimental and theoretical analysis of heat transfer augmentation from dimpled surface. International Journal of Engineering Research and Applications, 3(5), 19-23.

[9] Thianpong, C., Eiamsa-Ard, P., Wongcharee, K., \& EiamsaArd, S. (2009). Compound heat transfer enhancement of a dimpled tube with a twisted tape swirl generator. International Communications in Heat and Mass Transfer, 36(7), 698-704.

[10] Prasad, B. N., \& Saini, J. S. (1988). Effect of artificial roughness on heat transfer and friction factor in a solar air heater. Solar energy, 41(6), 555-560.
[11] Shafee, S.M., Gnanasekaran, K., Solomon, G.R. and Balaji, R., 2020. Preparation and analysis of novel paraffin based stable nano fluid dispersed with carbon nano tubes as effective phase change material for free cooling applications. Materials Today: Proceedings, 33, pp.4526-4532. 